\title{
Composition and Utilization of Urban Garden Space Using the Planting System Design Process
}

\author{
In-Kyoung Hong ${ }^{1}$, Hyung-Kwon Yun ${ }^{2 *}$, Sang-Mi Lee ${ }^{3}$, Young-Bin Jung ${ }^{3}$, and Mi-Ra Lee ${ }^{4}$ \\ ${ }_{1}^{1}$ Postdoctoral researcher, Urban Agricultural Research Division, National Institute of Horticultural and Herbal Science, Rural \\ Development Administration, Wanju-gun, Jeollabuk-do 55365, Korea \\ ${ }^{2}$ Senior researcher, Urban Agricultural Research Division, National Institute of Horticultural and Herbal Science, Rural Development \\ Administration, Wanju-gun, Jeollabuk-do 55365, Korea \\ ${ }^{3}$ Researcher, Urban Agricultural Research Division, National Institute of Horticultural and Herbal Science, Rural Development \\ Administration, Wanju-gun, Jeollabuk-do 55365, Korea \\ ${ }^{4}$ Research worker, Urban Agricultural Research Division, National Institute of Horticultural and Herbal Science, Rural Development \\ Administration, Wanju-gun, Jeollabuk-do 55365, Korea
}

\section{ABSTRACT}

Background and objective: Urbanization caused a reduction in urban green space and a lack of community spaces. An attempt to solve these problems, urban gardens, have become popular and are currently being implemented in various downtown areas. However, urban gardens have some inadequate aspects from a visual or landscape perspective. The goal of this study was to examine the possibility of an aesthetic and productive garden space by introducing cultivation methods through the planting system design process.

Methods: The design process using plants was classified and presented to suggest the importance of the landscape and aesthetic value. An urban garden space was designed according to the perspective of 'production scenery' and 'participation aesthetics'. According to the characteristics of the plant, urban gardens were divided into vertical type (corn, millet, sorghum), climbing type (kidney bean, cucumber, bitter gourd), and runner type (melon, watermelon, peanut). After classifying plants according to the shape of the root, the structure supporting climbing was installed and the crops were cultivated in an upright form with a tunnel.

Results: In the designed cultivation, each crop cooperates, without invading each other's space. Compared with the conventional cultivation, there was little difference in production, and management was made more convenient since weed outbreaks were effectively suppressed while runner type crops cover over the land's surface. Since the positions of each crop are clearly distinguished, the aesthetic value is improved by offering a sense of rhythm with a balanced design.

Conclusion: The results suggest that the cultivation methods through the plant system design process have aesthetic as well as productive value, and the design using plants, an infinite living resource, could lead to an expansion of the design field. Moreover, it would enable a sustainable symbiosis between industry and environment. There is potential for the design industry to make significant progress through collaboration with agriculture, horticulture, and landscape architecture.

Keywords: aesthetic landscape, companion plants, eco-friendly, sustainable, urban agriculture

\section{Introduction}

A place not only represents the location of a physical space, but also has more than that. Modern spaces in partic- ular emphasize the meaning and role of space, as the purpose of a space and the resulting change in behavior add to the intangible meaning arising from complex elements in the physical space (Seo and Lim, 2016). A space that

This study is supported by the Rural Development Administration's project (PJ01507602).

Received: October 20, 2020, Revised: November 25, 2020, Accepted: November 30, 2020

First author: In Kyoung Hong, inkyoung63@korea.kr, (1) https://orcid.org/0000-0002-7050-5413

*Corresponding author: Hyung Kwon Yun, yun0309@korea.kr, (1D) https://orcid.org/0000-0001-9973-4706 
is remembered as imagery in our mind through experience is a space recognized with a specific image and value through the human perceptual system, and has an overall characteristic that distinguishes a specific place from other places (Chio and Kim, 2001). With the recent improvement in consumption levels and information delivery media, the understanding and needs related to space have become advanced. Urban gardens also require efficient composition and management plans from a landscape perspective to improve the quality of life of urban residents and the comfort of urban landscapes, beyond a focus on simple plant-oriented production (Kim et al., 2008). Since modern people, in particular, do not have enough opportunities to access green spaces due to industrialization, it is an important time to improve the urban environment through the active use and spread of plants, and to strengthen human health and comfort of life (Cheong, 2017). However, as many urban gardens are considered only as production-oriented spaces, are not properly utilized, and are also damaging the aesthetic landscape, a comprehensive "design thinking" is becoming more important, which expands the perspective of the urban garden space from the physical/single level to the ecological/interchangeable experience level between users and spaces, and takes a systematic approach (Han and Kim, 2015). Planters containing plants should have an appropriate structure and shape for plant growth, going beyond a style limited to the aesthetics of the exterior, and apply the appropriate cultivation method in order to reduce unnecessary waste of time and money due to plant death or frequent plant replacement. Such planters should be also equipped with a cultivation frame (e.g. trellis) for climbing vegetable plants to attract vines to create conditions in which those can grow well; alternatively, it is necessary to communicate with the relevant users to improve convenience of management through a reduction of working hours via the use of irrigation facilities. This study was limited to cases in which plants were raised using separate planting containers and planting systems. In addition, the plants handled in the design case and growth experiment were selected as companion plants that had a good influence on each other or one side when planted together during kitchen garden cultivation. Companion plants have a landscape value along with diverse agricultural and envi- ronmental public functions, which include promoting the growth of nearby crops by absorbing nitrogen in the air and supplying nutrients deep in the soil; helping fertilize and pollinate nearby plants by attracting beneficial insects; protecting small plants by controlling shade of tall plants; or as a natural support, supporting the propagation of climbing plants and minimizing weeds in open fields (Hong et al., 2020). Plant growth experiments can identify whether the above-ground parts and fruits of plants are affected by the use of the planting system, and based on this, the system can be used in an urban garden using plants. Therefore, to create an urban garden with aesthetic landscape value, we intend to expand the value of the space and examine the possibility of an eco-friendly and efficient urban garden space, by introducing a cultivation method suitable for the physiology and characteristics of plants through the planting system design process. Based on this, this study aims to promote the expansion of the design area in a range of fields through convergent thinking using appropriate horticultural crops.

\section{Research Methods}

\section{Research scope}

This study carried out an urban garden design process, which was divided into the following two areas: the plant area that understands the physiology and characteristics of plants and introduces a cultivation method in a structure and shape suitable for plant growth, and the design area of the container where plants are planted (Cheong, 2017). Prior to the creation of an urban garden, a sustainable space composition from a landscape perspective and the efficient use of plants were planned and applied to the actual site; and the growth status according to the method of arranging crops was investigated in order to identify the appropriate quantity of plants in the space and whether or not plants could be used in terms of design (Fig. 1). 


\section{Research content}

\section{Research site}

The verification of space utilization was conducted from May to September 2020 (5 months) at the experimental field of Urban Agriculture Research Division of the National Institute of Horticultural and Herbal Science (NIHHS) under the Rural Development Administration, located in Iseo-myeon, Wanju-gun, Jeollabuk-do. A total of 6 planters were placed in a total area of $21 \mathrm{~m}^{2}$ (about 6.4 pyeong), based on two-planter groups, and symmetrical planting was repeated twice. Two planters were interlocked together to make them look like a group, and each group was placed at a distance of $1 \mathrm{~m}$ or more so that the crops

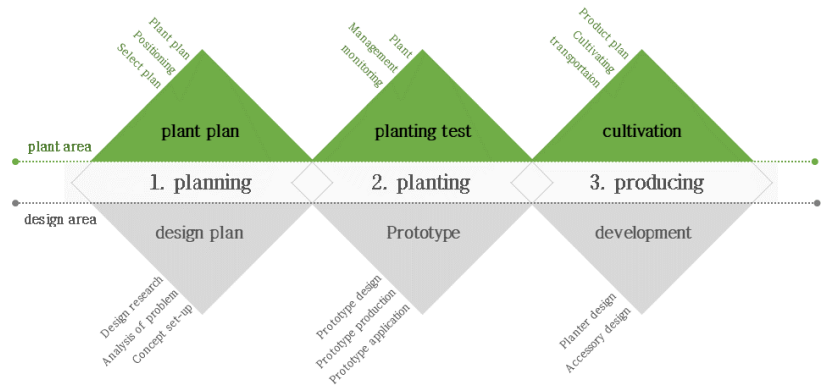

Fig. 1. Planting system design process

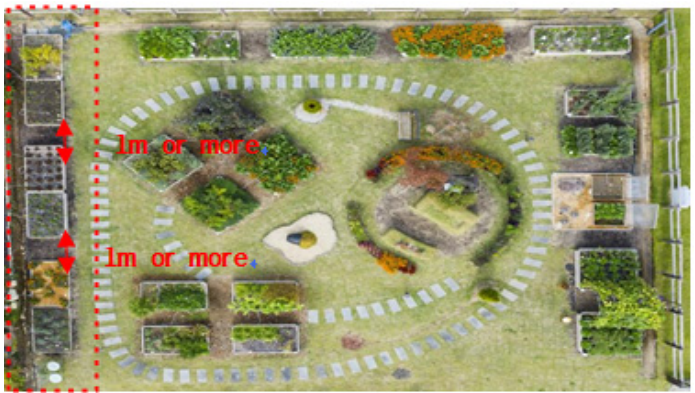

did not interfere with each other (Fig. 2).

\section{Soil analysis for plant growth}

Soil characteristics were investigated before planting for crop cultivation. Soil chemical properties were analyzed according to the soil chemistry analysis method of the Rural Development Administration, assessing factors such as $\mathrm{pH}$, organic matter content, $\mathrm{Av} \mathrm{P} 2 \mathrm{O} 5$ and $\mathrm{K}, \mathrm{Na}, \mathrm{Ca}$, and $\mathrm{Mg}$. The $\mathrm{pH}$ was measured using the glass-electrode method, the organic matter content using the Tyurin method, the effective phosphate using the Lancaster method, and the cation through ICP. The soil's physical properties were measured for each experimental plot under conditions of soil cone type $1.0 \mathrm{~cm}^{2}$ of crops and their planting combinations using Penetrologger 6.0, an intrusive digital hardness tester.

The physicochemical properties of the soil measured for each experimental plot were found to be sandy loam with $\mathrm{pH} 6.89$, EC 1.02 , and an average of $165.37 \mathrm{mg} / \mathrm{kg}$ of available phosphate (Table 1). It was suitable for crop growth, as it meets the criteria for cultivation soil of the crops to be planted (RDA, 2019b).

\section{Crop selection and planting method}

For the purpose of increasing the space utilization, plants

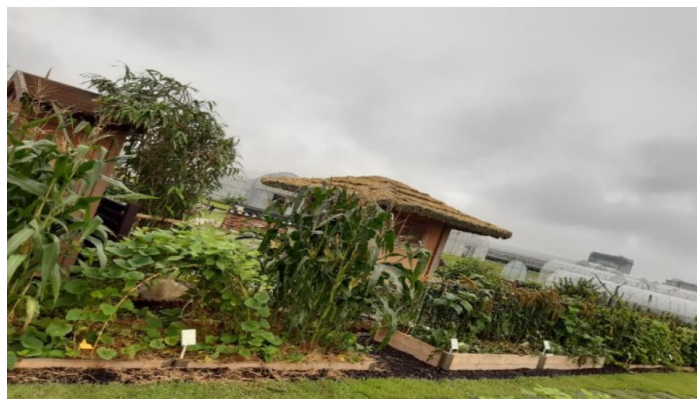

Fig. 2. Composition of urban garden space using the planting system design process

Table 1. Characteristic of soil on cultivation plot

\begin{tabular}{|c|c|c|c|c|c|c|c|c|c|}
\hline \multirow{2}{*}{ Div. } & \multirow{2}{*}{$\frac{\mathrm{pH}}{(1: 5)}$} & \multirow{2}{*}{$\frac{\mathrm{EC}}{(\mathrm{dS} / \mathrm{m})}$} & \multirow{2}{*}{$\frac{\mathrm{Av} \cdot \mathrm{P}_{2} \mathrm{O}_{5}}{(\mathrm{mg} / \mathrm{kg})}$} & \multicolumn{4}{|c|}{ Exchangeable. Cation $(\mathrm{cmol}+/ \mathrm{kg})$} & \multirow{2}{*}{$\frac{\mathrm{NH}_{4}-\mathrm{N}}{(\mathrm{mg} / \mathrm{kg})}$} & \multirow{2}{*}{$\frac{\mathrm{NO}_{3}-\mathrm{N}}{(\mathrm{mg} / \mathrm{kg})}$} \\
\hline & & & & $\mathrm{K}$ & $\mathrm{Ca}$ & $\mathrm{Mg}$ & $\mathrm{Na}$ & & \\
\hline G1 & 6.89 & 1.02 & 163.60 & 0.59 & 5.31 & 2.77 & 0.17 & 11.83 & 4.20 \\
\hline $\mathrm{G} 2$ & 6.89 & 1.02 & 160.15 & 0.60 & 5.39 & 2.88 & 0.17 & 10.15 & 0.00 \\
\hline G3 & 6.89 & 0.97 & 172.38 & 0.56 & 5.01 & 2.93 & 0.16 & 11.06 & 0.00 \\
\hline Mean \pm SD & $6.89 \pm 0$ & $1 \pm 0.02$ & $165.37 \pm 6.31$ & $0.58 \pm 0.02$ & $5.24 \pm 0.2$ & $2.86 \pm 0.08$ & $0.17 \pm 0$ & $11.01 \pm 0.84$ & $1.4 \pm 2.42$ \\
\hline
\end{tabular}


and companion plants verified through the report of Chae et al. (2019) were selected as a group for the garden. Based on the biological growth conditions of plants, various limiting factors required for the planting design of plants were classified, including the growing environment in which plants grow, the uses of plants, purpose of plant cultivation, plant grower, technical method of cultivation, and conservation and growth of plants. All nine crops selected are annual and photophilic plants. The plants can be divided by root shape into fibrous root system plants and taproot system plants: Gramineae, vertical type crops, all have fibrous roots, and of these, corn, millet, and sorghum were selected. Of the climbing type, kidney beans (Leguminosae) and cucumbers (Cucurbitaceae) have tap roots, and bitter gourds have fibrous roots. Finally, for runner type planted in the lower part, melons (Leguminosae) and peanuts (Cucurbitaceae) have tap roots, and mini watermelons have fibrous roots. These crops were arranged by properly mixing Gramineae, Leguminosae, and Cucurbitaceae according to the root shape (Table 2). In particular, Leguminosae are essential crops in the cropping system for eco-friendly agriculture, and are the most suitable ones for eco-friendly crop rotation by alleviating replanting failure, improving the soil, and fixing atmospheric nitrogen (RDA, 2014). In addition, when rice straw was covered on the surface of the soil to reduce the evaporation of water on the ground and prevent fruit softening, weed outbreaks were minimized; the confirmed findings in this area will be reported separately.

Vertical type crops were first arranged, but planted at $5: 8$ points of the total area of the planter so as not to create a barrier, and runner type crops were planted underneath them (Fig. 3). In particular, for climbing type crops, various cultivation frames were installed so that the fields could be operated and managed efficiently. Planting more than two types of crops together offers advantages such as efficient use of space, rational use of fertilizer components, reduction of weeds, and increased stability against disasters (Oh, 2013). Various horticultural crops planted in this field were sown on March 17, grown as seedlings in a glass greenhouse, and planted on May 4.

\section{Survey and analysis method}

To verify the space utilization, the growth status of crops

Table 2. Scientific and family name on trial crop

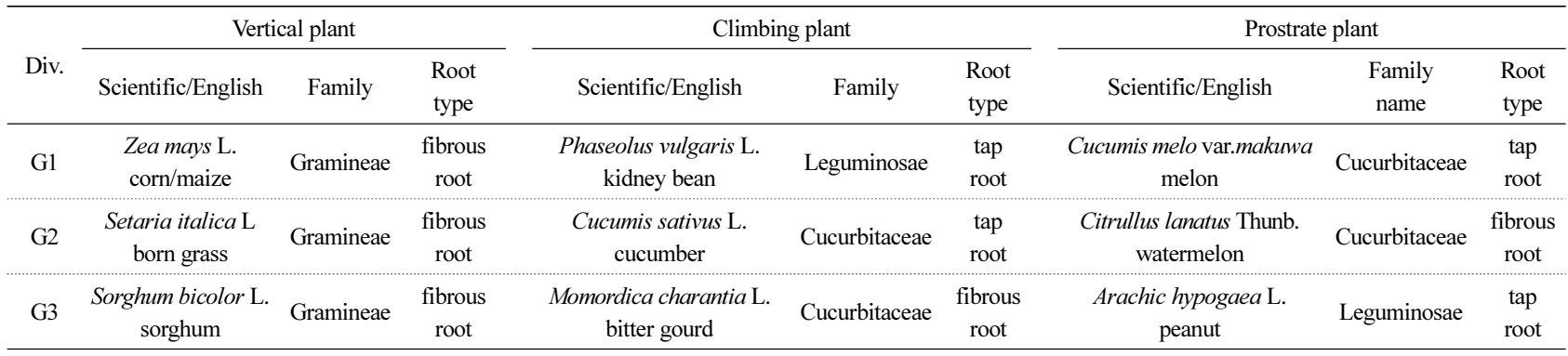
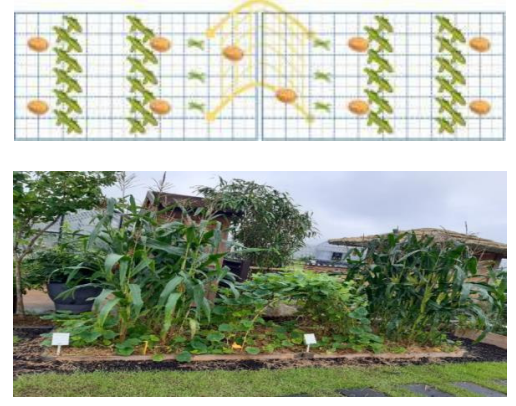

"Group $1<$ corn, kidney bean, melon>"
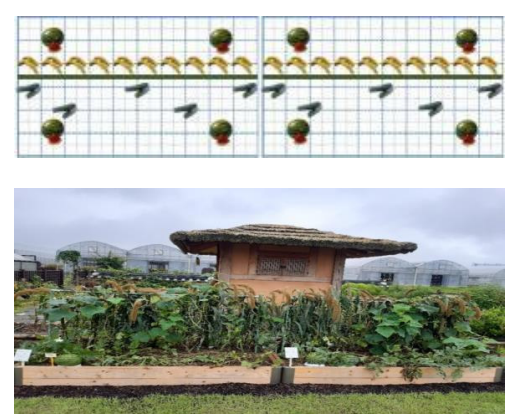

"Group $2<$ born grass, cucumber, watermelon $>"$
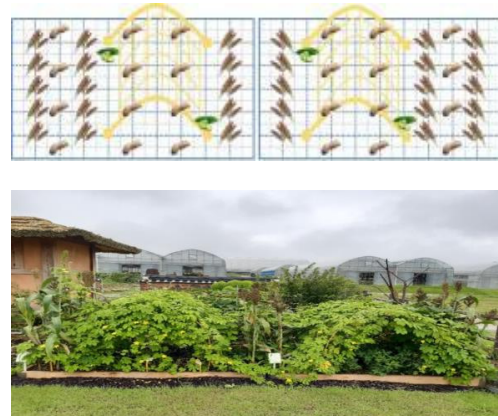

"Group $3<$ sorghum, bitter gourd, peanut>"

Fig. 3. Crops \& planting method by experimental group. 
was investigated every Thursday after planting, by calculating the covering rate according to the growth of the crops using a $100 \times 100 \mathrm{~cm}$ quadrate. The plant height until 3 repetitive harvestings for each crop, and the length and weight of fruits after harvesting were investigated, and the related data were arranged in Excel. Based on these data, the growth mean and standard deviation were calculated using IBM SPSS statistics Ver 25. Growth and yield of each crop were in accordance with the Standard Survey for Agricultural Testing and Research of the Rural Development Administration (RDA, 2012a).

\section{Results and Discussion}

\section{Site creation}

To expand the field of landscape value in the urban garden space, it is necessary to change the way designers think about space and the experiential elements in a space. In modern urban garden spaces, it is important to form a sense of place that involves time and empirical concepts. A sense of place is formed through a continuous process of interaction between the users and all the attributes inherent in a place, along with all the external elements. This study was approached from two perspectives as an empirical study: "emotional experience," where styling of space is important as a one-dimensional experience, and "functional experience," which is all experiential areas generated by the formation of place (Fig. 4). For emotional experience, separate variable planters for plants were installed, and a planting system for functional experience was created by dividing the space so that people can communicate and experience together in every direction.

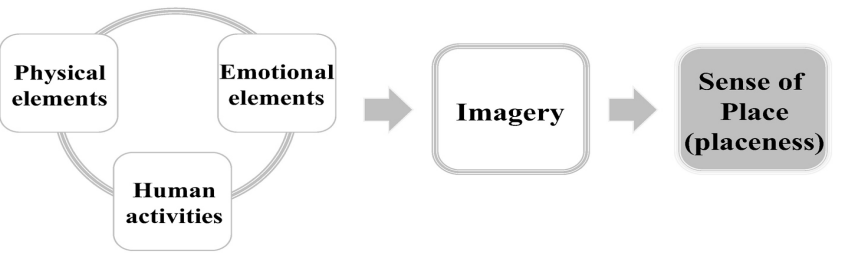

\section{Use of planting system}

Planters, which are containers for planting and growing plants; and the tools and accessories necessary for planting including planters; as well as planter installation, cultivation and management on platters, are collectively referred to as a "planting system". The system is broadly divided into a plant area and a design area. In other words, the plant area involves biological processes such as planting and growth of plants, and the design area refers to the process of design development for products and systems (Cheong, 2018).

\section{Design area}

The design area of a planting system is divided into planters that hold plants, accessories that help planting and the growth of plants, and the substructure necessary for planter installation, and consists of a system that is structurally combined with the design of each element (Table 3).

Typical garden boxes used for cultivation have the advantage of being cheap or light depending on the materials, but also have weaknesses such as poor durability and vulnerability to mass cultivation of plants (Cheong, 2017). The planter material used in this study is $38 \mathrm{~mm}$ red pine, which is durable and can be used for a long time, and is also easy to assemble and enables us to cultivate a large number of plants. In addition, the planters were built in a variable type that users can easily change, which can be adjusted to the desired size as needed, and the height can also be adjusted using an oval-shaped bracket on the corner. Compared to conventional open-field cultivation, this entails a high cost for initial facility investment, but allows us to expect effects such as labor saving and stable crop production, and has the advantage of enabling us to properly control space and produce crops according to the char-
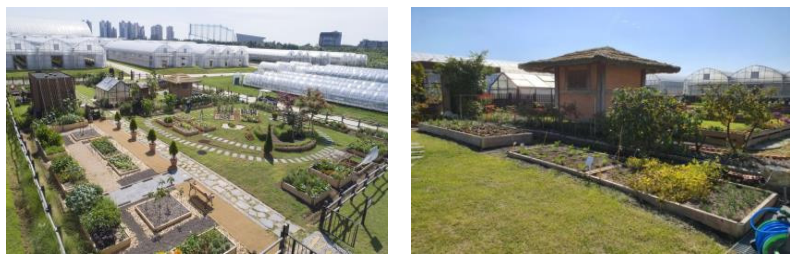

Fig. 4. Components for the formation of place and the site created. 
Table 3. Planting system design elements

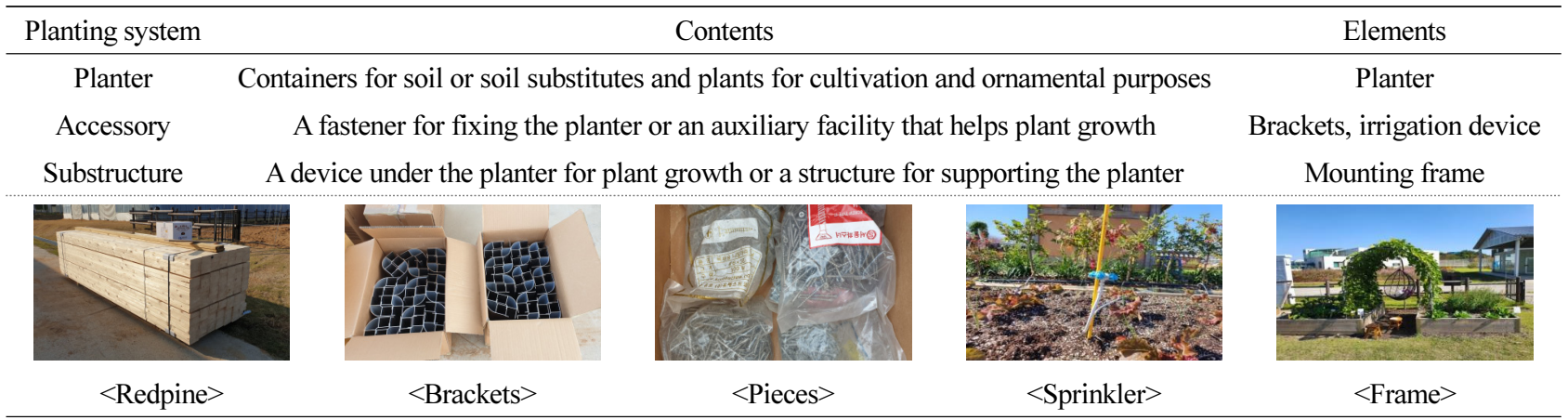

Table 4. Planter \& cultivation type, others for climbing plant

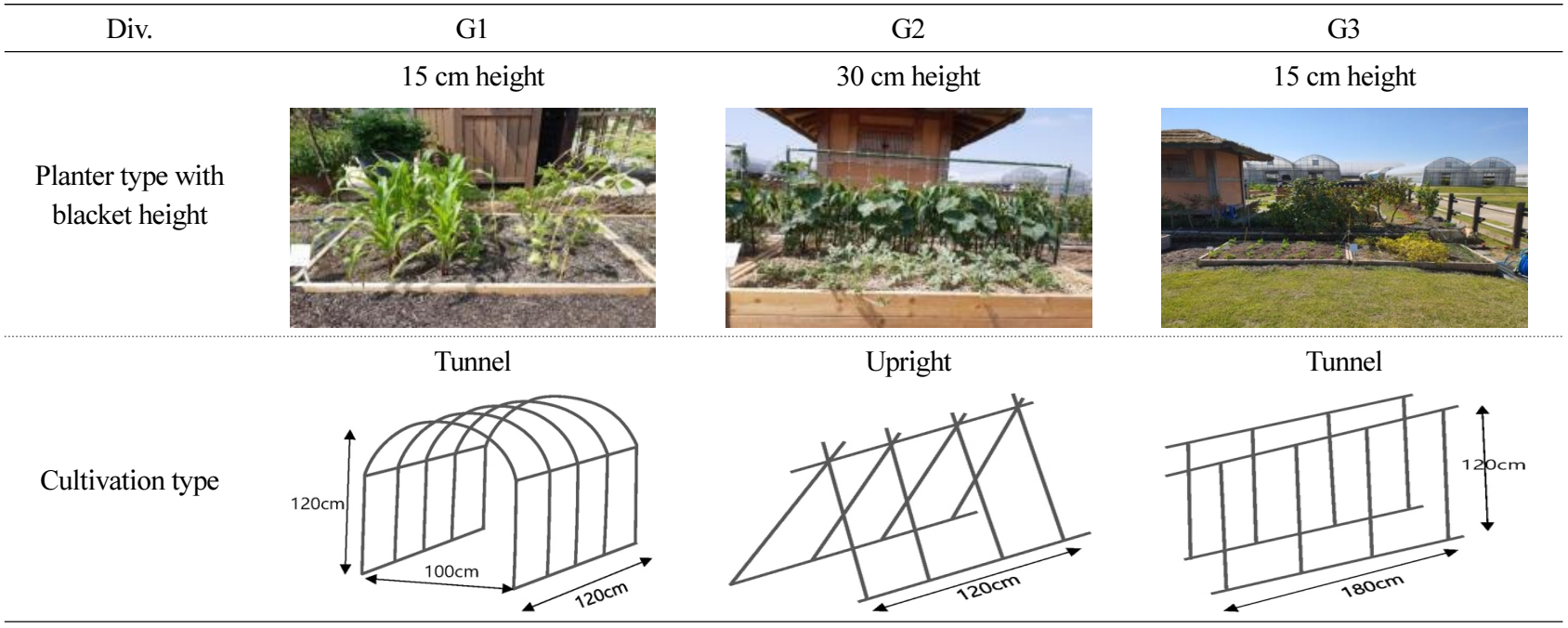

acteristics of plants. As this study was carried out in the experimental field planned in a limited space of $21 \mathrm{~m}^{2}$, considering the areas that would be managed so that the utilization of space is increased and crops of each group are not close to each other, $2 \mathrm{~m}$ wide x $1.2 \mathrm{~m}$ long (approximately 0.7 pyeong) planters were constructed in two types, $15 \mathrm{~cm}$ and $30 \mathrm{~cm}$ high. Based on the characteristics of the plants in the planters, they were classified into three types: vertical type in the upper layer, climbing type in the middle, and runner type for the lower layer; and planting of each crop was planned to increase the use of space as much as possible by securing each location without competing with each other. In addition, to increase the efficiency of space, tunnel type and upright trellis were installed for climbing type crops so that the stems were naturally attracted (Table 4). Depending on the height of vertical type crops, a single-tier trellis was installed in experimental plot 1 (G1), a two-tier trellis in experimental plot 2 (G2), and a single-tier trellis in experimental plot 3 (G3), so that the planter alone can have a morphological rhythm according to the height. Finally, a sprinkler for each planter was installed separately to enable convenient management through a smooth water supply to the crops. All cultivation frames were uniformly installed at a height of $1.2 \mathrm{~m}$ to give a sense of unity without distraction according to the design (Table 4).

\section{Plant area}

\section{(1) Covering rate}

The height of 9 plants planted in the planter was measured. Changes in plant growth were investigated 75 days after planting. As for plant coverage within the quadrant of each experimental plot, Experimental plot 1 (G1) 
Table 5. Crop's coverage percent of experimental zones

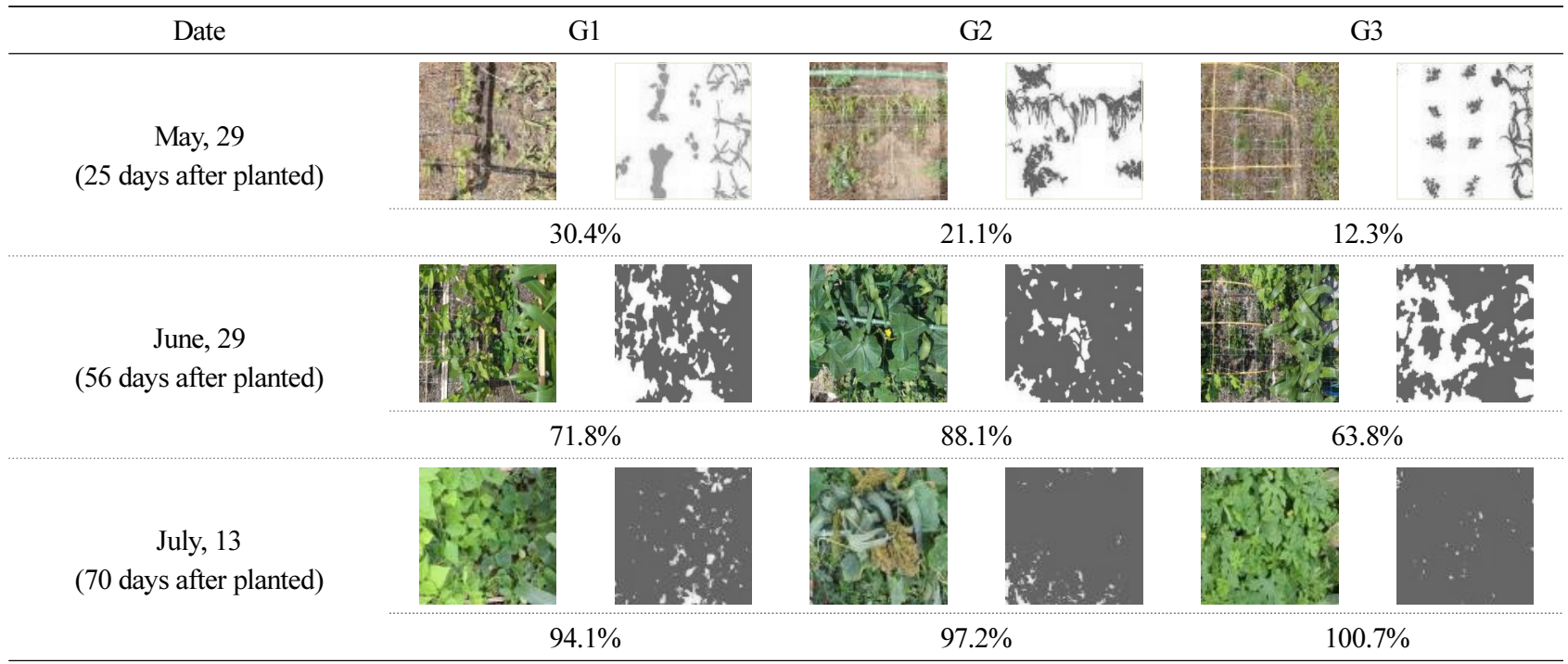

had good initial growth, and saw a coverage rate of $30.4 \%$ 25 days after planting, and of $94.1 \%$ in mid-July, covering almost the entire plot. Experimental plot 2 (G2) covered all the ground with a coverage rate of $97.2 \%$ in mid-July, and Experimental plot 3 (G3) had only a little coverage at the beginning, and then covered the entire field in mid-July (Table 5). In particular, Leguminosae crops have a high amount of nitrate nitrogen released when cultivated for the purpose of circulating soil nitrogen (Sainju et al., 1998), and a part of crop nitrogen requirement was covered by fixing air nitrogen with leguminous bacteria (RDA, 2012b). Coverage rate measurement, which determines the degree of plant growth, is effective in weed control and can reduce management efforts, and thus has an effect on crop yield.

\section{(2) Crop growth}

The corn cultivated in G1 (Waxy Corn No. 4) grew somewhat smaller than the average of $234.4 \mathrm{~cm}$ (Park, 2007) in conventional cultivation. Compared to the report of RDA (2014), there was a slight difference at 3.3 tillers per plant, but the length and diameter of the ears were not different, and the ears were uniform, so the ear weight was higher than $25 \mathrm{~g}$, and the marketability was excellent. Nitrogen-fixing bacteria grew near the root and helped the growth of corn (RDA, 2012b), and climbing type cranberry beans grown as companion plants were $1 \mathrm{~m}$ shorter than conventional cultivation, but the length and width of the pods were not different. The number of beans per pod was 4-6, and the weight of 100 seeds was in the range of 30-80 g, which was the same as reported by RDA (2018c). Runner type melons planted as a companion plant to corn were cultivated with a trimmed vine length of $110 \mathrm{~cm}$, and the height and harvested fruits were similar to those reported by RDA (2018b), but the average fruit weight was somewhat lower. According to the RDA (2018b) report, the reasons for this difference are: during the day, the temperature is high and the soil temperature rises, so moisture absorption by plants is actively progressed, and the transpiration is active, but the temperature gradually decreases at night, so the moisture absorption is active, but the transpiration decreases rapidly. To cope with this, rapid changes in soil moisture should be prevented in the early stage of fruit enlargement and care should be taken to prevent high humidity in the late stage; management should be carried out to ensure that there is no sudden change in soil moisture or air humidity during fruit growth.

The vertical type crop cultivated in G2 was millet (Glutinous Foxtail Millet (Setaria italica Beauv.) variety 'Samdachal') and the plant length was shorter than that of conventional cultivation (culm length $128 \mathrm{~cm}$, panicle length $28 \mathrm{~cm}$, plant height $156 \mathrm{~cm}$ ), but the ear length was $10 \mathrm{~cm}$ long in a cylindrical shape, and it was advantageous for eco-friendly garden cultivation because it was strong against pests and diseases (RDA, 2013). White cu- 
cumbers (Dadagi), a climbing type crop for cultivation in spring and autumn were cultivated, and the growth showed little difference compared to that of conventional cultivation, but the shape of the cucumber fruits is deformed, e.g., curved. This is due to a lack of nutrients, and this continuous management is required by fertilizing them at an appropriate time (RDA, 2019a). Mini watermelons, a runner type crop, were grown, which were the varieties 'Ggoggoma' and 'Sambokggul' purchased from NIHHS. When the watermelons weighed about $1-1.5 \mathrm{~kg}$, the fruits were erected and straw or a stand was laid under them, which helped suppress the occurrence of fruit diseases or deformations, resulting in no difference in growth compared to the conventional cultivation (RDA, 2018e). However, since millet, a vertical type crop, has difficulty supporting the weight of cucumber fruit, it requires a cultivation frame when grown with such a climbing type crop as a companion plant.

Sorghum, a vertical type crop, cultivated in G3, was 'white sorghum', and the plant height was no different from that reported by Kim (2013), but the panicle length was
$8 \mathrm{~cm}$ shorter (RDA, 2018d). Bitter gourd, a climbing type crop, was a super-large variety, Okinawa No. 2, and there was no difference in length from that reported by RDA (2018a), but the size was slightly smaller, at $15 \mathrm{~mm}$ in diameter and $162 \mathrm{~g}$ in weight. As a runner type companion plant, the Virginia-type peanut (Arachis hypogaea L.) was cultivated, but it had a late flowering period, a long maturation period, a low oil content, and a long dormancy period (RDA, 2012b). For bitter gourds, the number of seeds per plant was remarkably reduced due to poor growth and yellowing of the above-ground part, as the shade fell on the ground during the growth period (Table 6).

\section{Conclusion}

With the rapid development of our modern society, the unified residential culture that emerged caused a reduction in urban green space and community spaces. To solve these urban problems, urban farming, also known as the "urban garden" has emerged, and is currently being carried out

Table 6. Growth survey results of 9 crops in this study

\begin{tabular}{|c|c|c|c|c|c|c|c|c|c|c|c|c|}
\hline \multirow[b]{2}{*}{ Div. } & \multirow[b]{2}{*}{ Type $^{z}$} & \multirow[b]{2}{*}{ Crop } & \multicolumn{2}{|c|}{ Seed } & \multicolumn{3}{|c|}{ Crop growth } & \multirow{2}{*}{$\begin{array}{l}\text { Crop } \\
\text { Length } \\
(\mathrm{cm})\end{array}$} & \multicolumn{4}{|c|}{ Ear / Pod / Fruit } \\
\hline & & & $\begin{array}{l}\text { Length } \\
(\mathrm{mm})\end{array}$ & $\begin{array}{l}\text { Width } \\
(\mathrm{mm})\end{array}$ & Initial & Middle & Harvest & & $\begin{array}{l}\text { Length } \\
\text { (mm) }\end{array}$ & $\begin{array}{l}\text { Diameter } \\
(\mathrm{mm})\end{array}$ & $\begin{array}{l}\text { Weight } \\
\text { (g) }\end{array}$ & $\begin{array}{l}\text { Quantity } \\
\text { (ea) }\end{array}$ \\
\hline \multirow{3}{*}{ G1 } & $\mathrm{V}$ & Zea mays L. & 8.74 & 6.73 & & & & $144.25 \pm 99.56$ & $17.11 \pm 2.39$ & $43.85 \pm 2.24$ & $194.65 \pm 30.54$ & $2.5 \pm 1.7$ \\
\hline & $\mathrm{C}$ & $\begin{array}{l}\text { Phaseolus vulgaris } \\
\text { L. }\end{array}$ & 17.95 & 10.75 & & & & $107.50 \pm 77.67$ & $10.00 \pm 6.73$ & - & $34.5 \pm 12.1$ & $4.50 \pm 3.70$ \\
\hline & $\mathrm{R}$ & $\begin{array}{l}\text { Cucumis melo var. } \\
\text { makuwa }\end{array}$ & 5.30 & 2.68 & & & & $112.75 \pm 78.37$ & $9.93 \pm 1.76$ & $67.61 \pm 9.31$ & $245.31 \pm 84.27$ & $5.25 \pm 4.79$ \\
\hline \multirow{3}{*}{$\mathrm{G} 2$} & $\mathrm{~V}$ & Setaria italica L. & 2.06 & 1.59 & & & & $83.13 \pm 55.89$ & $28.75 \pm 19.17$ & - & - & $1.25 \pm 0.96$ \\
\hline & $\mathrm{C}$ & Cucumis sativus L. & 8.59 & 3.52 & & & & $265 \pm 176.87$ & $26.73 \pm 4.06$ & $42.15 \pm 5.97$ & $274.10 \pm 88.84$ & $6.5 \pm 6.6$ \\
\hline & $\mathrm{R}$ & $\begin{array}{l}\text { Citrullus lanatus } \\
\text { Thunb. }\end{array}$ & 7.84 & 5.30 & & & & $306.5 \pm 27.0$ & $18.22 \pm 2.08$ & $156.32 \pm 20.40$ & $2,370 \pm 810$ & $4 \pm 1.15$ \\
\hline \multirow{3}{*}{ G3 } & $\mathrm{V}$ & Sorghum bicolor L. & 3.86 & 3.53 & & & & $96.25 \pm 64.34$ & $17.5 \pm 11.7$ & - & - & $1 \pm 0.82$ \\
\hline & $\mathrm{C}$ & $\begin{array}{l}\text { Momordica } \\
\text { charantia L. }\end{array}$ & 14.43 & 8.07 & & & & $201.75 \pm 136.61$ & $25.06 \pm 4.83$ & $37.93 \pm 15.17$ & $190 \pm 140$ & $4 \pm 3.37$ \\
\hline & $\mathrm{R}$ & $\begin{array}{l}\text { Arachic hypogaea } \\
\text { L. }\end{array}$ & 19.65 & 9.01 & & & & $27.25 \pm 18.57$ & 3.39 & - & 105.85 & 9.4 \\
\hline
\end{tabular}

${ }^{\mathrm{z}} \mathrm{V}=$ vertical, $\mathrm{C}=$ climbing, $\mathrm{R}=$ Runner 
in many parts of cities. But despite having the function of securing green space and revitalizing the community, there are many insufficient aspects of the design of such urban gardens from a visual or landscape perspective. With this as the background, this study intended to propose the importance of landscape's value by considering a city as an organism in which place and culture are converged, not only from a functional point of view; and also separately suggested a design process using plants. As the landscape's value can be explained from an aesthetic point of view, this study used the planting system design process from the viewpoint of "productive landscape" and "participatory aesthetics" to create a space with design elements of planters, accessories, and sub-structures. The cultivated plants were first classified according to their characteristics into vertical type (corn, millet, sorghum), climbing type (kidney bean, cucumber, bitter gourd), and runner type (melon, watermelon, peanut). Then, for proper placement, the crops were grouped according to their root type; climbing type crops were cultivated by installing structures (e.g., trellises) that attract and support their vines in tunnel or upright forms. As a result, in G1 (15 cm height/tunnel type), one tunnel cultivation frame was installed in the form of a link on two planters, so that each crop grew well as a companion plant without invading other plants' space. Compared with the conventional cultivation, there was almost no difference in production, but due to transpiration caused by the temperature difference, the melons were dehiscent, so continuous management was required. In G2 $(30 \mathrm{~cm}$ height/upright type), the crops were grown in a mutually dependent manner, and due to there being no space between the plants, they were frequently exposed to pests, but there was no difference from conventional cultivation in their growth, with the exception of the cucumbers which were deformed, such as curved, requiring nutrient management. In G3 $(15 \mathrm{~cm}$ height/tunnel type), tunnels were installed for each planter, which caused insufficient space between the plants, resulting in poor plant growth. Accordingly, it was found that the variable planter, which can be adjusted according to the characteristics of the plants, is effective in terms of the operation and management of an urban garden, and the G1 system, where each plant has its own positions, is the most efficient for plant growth. In particular, as run- ner type crops dominated the surface, weed outbreaks were suppressed, and labor was reduced by the installation of sprinklers as irrigation facilities, improving the convenience of management. In addition, the size of the plants showed differences in growth at each position, giving a sense of unity and rhythm throughout the entire space. This enabled us to grasp a remarkable difference from the simple planting shown in the conventional vegetable garden.

Design using plants, which are an infinite living resource, leads to expansion of the design area, and enables sustainable symbiosis between industry and environment; the design industry will expand and develop through cooperation and convergence with the fields of agriculture, horticulture, and landscape. Based on this study, there should be active discussions in the future in the fields of agriculture and horticulture in terms of plant production technology, and landscape and design in the aspect of plant utilization; and interdisciplinary follow-up research in more diverse fields is needed.

\section{References}

Chae, Y., I.K. Hong, S.M. Lee, and Y.B. Jung. 2019. Development of functional planting model and manual for diversification of vegetable garden (p.111). RDA report, Wanju, Korea: Rural Development Administration.

Cheong, Y.S. 2018. A study on the planting system design and process. Doctoral dissertation, Kyonggi University, Suwon, Korea.

Chio, M.J. and M.O. Kim. 2001. Empirical analysis of components and economic values of the 'placeness': The cases of daehak and rodeo streets in Seoul. J. Korea Plan. Assoc. 36(2):153-162.

Han, J.E. and S.I. Kim. 2015. The efficiency of service design methodology in the space design: Focused on the apartment design manual development. J. Digit. Des. 15(1):397-407.

Hong, I.K., H.K. Yun, Y.B. Jung, S.M. Lee, and B.K. Lee. 2020. Classification of crops by type of companion plant (Abstr.). J. People Plants Environ. Vol. 23 (Suppl. I ): 11.

Kim, I.H., M.T. Lim, and Y.S. Park. 2008. A study on 
the sustainable design methods for urban landscape. J. Resid. Environ. Inst. Korea 6(1):53-67.

Kim, T.Y. 2013. Growth and yield characteristics of foxtail millet, proso millet and sorghum according to sowing date in middle area in Korea. Master's thesis, Dankook University, Cheonahn. Korea.

Oh, M.G. 2013. Effect of mixed-sowing of legume and applying of cattle manure on the productivity of rye. Master's thesis, Daegu University, Daegu, Korea.

Park, B.Y. 2007. Yield and table quality of the new developed colored waxy CNU maize hybrids. Master's thesis, Chungnam National University, Daejeon, Korea.

Rural Development Administration. 2012a. 5th Edition Agricultural science and technology: Research survey analysis standards. Suwon, Korea: Author.

Rural Development Administration. 2012b. Hign quality peanut safety production technology. Suwon, Korea: Author.

Rural Development Administration. 2013. Small area food crop technical information:Millet. Suwon, Korea: Author.

Rural Development Administration. 2014. Manual for organic cultivation of beans, wheat and corn. Suwon, Korea: Author.
Rural Development Administration. 2018a. Bitter gourd, Wanju, Korea: Author.

Rural Development Administration. 2018b. Oriental melon, Wanju, Korea: Author.

Rural Development Administration. 2018c. Pulse crops, Suwon, Korea: Author.

Rural Development Administration. 2018d. Sorghum, Wanju, Korea: Author.

Rural Development Administration. 2018e. Watermelon, Wanju, Korea: Author.

Rural Development Administration. 2019a. Cucumber, Wanju, Korea: Author.

Rural Development Administration. 2019b. Vegetable soil management, Wanju, Korea: Author.

Sainju, U.M., B.P. Singh, and W.F. Whitehead. 1998. Cover crop root distribution and its effects on soil nitrogen cycling. Agron. J. 90(4):511-517. https://doi.org/10.213 4/agronj1998.00021962009000040012x

Seo, D.J. and J.H. Lim. 2016. A study about public space pattern for place identity. J. Korea Inst. Spat. Des. 11(1):89-99. https://dx.doi.org/10.35216/kisd.2016.11.1.89 